\title{
BILOCAL AUTOMORPHISMS
}

\section{Lajos Molnár, Peter Šemrl And Ahmed Ramzi Sourour}

Abstract. We prove that every bilocal automorphism of a matrix algebra is either an inner automorphism, or an inner anti-automorphism, or it is of a very special degenerate form. Bijective continuous bilocal automorphisms of a unital standard operator algebra on an infinitedimensional separable complex Banach space are automorphisms.

Mathematics subject classification (2010): 15A86, 47B49.

Keywords and phrases: Bilocal automorphism, standard operator algebra, matrix algebra.

\section{REFERENCES}

[1] P. R. CHERNOFF, Representations, automorphisms and derivations of some operator algebras, J. Funct. Anal. 12 (1973), 275-289.

[2] J. CUI AND J. Hou, Linear maps between Banach algebras compressing certain spectral functions, Rocky Mountain J. Math. 34 (2004), 565-584.

[3] R. V. Kadison, Local derivations, J. Algebra 130 (1990), 494-509.

[4] D. R. Larson and A. R. Sourour, Local derivations and local automorphisms of $B(X)$, in: Proc. Sympos. Pure Math. 51, Part 2, Providence, R.I., 1990, 187-194.

[5] L. Molnár, Selected Preserver Problems on Algebraic Structures of Linear Operators and on Function Spaces, Lect. Notes Math. 1895, Springer-Verlag, Berlin-Heidelberg, 2007.

[6] L. MOLNÁR, Bilocal *-automorphisms of $B(H)$, preprint.

[7] R. I. OVSEPIAN AND A. PEŁCZYŃSKI, On the existence of a fundamental total and bounded biorthogonal sequence in every separable Banach space, and related constructions of uniformly bounded orthonormal systems in $L^{2}$, Studia Math. 54 (1975), 149-159.

[8] C. DE SEguins PAZZis, The singular preservers of non-singular matrices, Linear Algebra Appl. 433 (2010), 483-490.

[9] L. RodmAn AND P. ŠEMrL, A localization technique for linear preserver problems, Linear Algebra Appl. 433 (2010), 2257-2268.

[10] O. TAUSS KY AND H. ZASSENHAUS, On the similarity transformation between a matrix and its transpose, Pacific J. Math. 9 (1959), 893-896.

[11] J. Zhu AND C. Xiong, Bilocal derivations of standard operator algebras, Proc. Amer. Math. Soc. 125 (1997), 1367-1370. 